\title{
The Role of Task Complexity in Valuation Errors Analysis in a Developing Real Estate Market
}

The real estate valuation literature on Sub-Saharan Africa (SSA) shows a growing concern over valuation errors especially wide variation in valuations. Although there have been increased business and investment activities in the last decade or more in the region, these valuation errors pose a challenge to the maturity of SSA real estate markets as valuations promote transparency and support efficient operation of property markets. Based on archival and survey data, as well as insights from the task complexity discourse, this study examines the extent of variations in valuations and the effect of complex valuation tasks on the levels of the variations in Ghana. The study finds high levels of variations in valuation opinions of $33.6 \%$ and $63 \%$ for the archival and survey data respectively. These levels of variations are substantially higher than have been reported in the literature for advanced markets suggesting that the concerns of valuation errors in SSA may be well grounded. Consistent with theory, it is further established that variations in valuation opinions may be more pronounced in comparatively more complex assignments. These findings have several implications including possible loss of confidence of market players in valuations, heightening of market uncertainty and increase in transaction costs.

Keywords: Errors, Real Estate, Task Complexity, Valuation, Variation

\section{Introduction}

Sub-Saharan Africa (SSA) is increasingly becoming a destination of global investment in spite of challenges, such as inadequate infrastructure, trade barriers, skills shortage, low productivity and diseases (PricewaterhouseCoopers (PWC), 2012; International Monetary Fund (IMF), 2015). This recent upsurge in global investment interest in the region is partly credited to good economic performance, rapid urbanisation, increase in the middle-class population and consumerism, and improved transparency in market operations (Jones Lang LaSalle (JLL), 2014; Baffour Awuah et al., 2014; IMF, 2015). Real estate is one sector where investment interest continues to soar (JLL, 2014; FTSE Global Markets, 2015). Apart from housing, growth in other sectors in constituent SSA economies, such as telecommunication, manufacturing, retailing, outsourcing, finance and hospitality has resulted in increase in demand for commercial real estate (JLL, 2014; Viruly and Hopkins, 2014). 
Professional property valuation service is vital to real estate business and market operations (Lorenz and Lützkendorf, 2008). Reliable valuations could constitute important tools for good governance and transparent business activities. Valuations are, therefore, of immense importance to individuals, institutions and corporations, local and central governments, businesses and investors in SSA. The survival of the current real estate investment drive and the maturity of property markets in SSA therefore are, in part, dependent on the standard of valuations produced in the region. Nonetheless, there are growing concerns over the standard of valuations produced by valuers in SSA. In particular, concerns over large differences between values estimated by two or more valuers on the same property have been raised in several quarters. For instance, in a 2014 report, PWC notes that the lack of consensus on valuations is one of the main reasons for the failure of transactions that enter formal due diligence in developing economies, such as those of SSA. Although a few studies, such as Babawale and Ajayi (2011) have been conducted in some constituent economies, the growing concerns with the standard of valuations in SSA particularly variations in valuations and their extent are largely based on anecdotal evidence. Unlike the developed world, such as the United Kingdom (UK), United States of America (USA) and Australia where a number of studies have been conducted into the extent of valuation errors, not much work has been done in this area in SSA. Since the seminal work of Hager and Lord (1985), several works, such as Brown (1985, 1992), Investment Property Databank (IPD) and Driver Jones (1988, 1990), Cullen (1994), Mcallister (1995), Matysiak and Wang (1995), Adair et al. (1996), Blundell and Ward (1999) have examined the extent of valuation errors in the UK. The majority of these studies report that valuations in the UK are fairly accurate and errors seem to be within reasonable bounds. The results of similar studies that have been conducted in the USA and Australia are generally consistent with the findings in the UK studies. This suggests that errors in valuations may not be pervasive in developed markets. However, the lack empirical evidence on the extent of errors in valuations across the SSA region prevents policy makers and professional bodies from understanding the nature of the problem and to prescribe appropriate remedies.

This study investigates two main issues relating to variations in valuations in Ghana, a developing country that has experienced a surge in investor interest over the past two decades, but also faces data challenges that hamper the delivery of professional valuations. Firstly, the study investigates the extent of variation in valuations produced by professional valuers in Ghana. It is 
important to state that two major determinants of valuation errors, which are lack of reliable market data and market uncertainties, have been long standing features of the real estate market in Ghana and many SSA property markets. For instance, the rapid fluctuations in market prices, and quotation and payment of agreed prices in foreign currencies are sources of market uncertainty. Also, the lack of adequate reliable property/market data has been well documented in the literature (Gough and Yankson, 2000; Mahama and Antwi, 2006; Obeng-Odoom and Ameyaw, 2011 ). Consequently, one would expect greater level of errors particularly variation in valuations in SSA countries than have been reported for more developed markets.

Secondly, the study examines the effect of complex valuation tasks on the levels of variation in the valuation opinions based on insights from the task complexity theory. Complex tasks have been noted to have adverse effects on people's ability to integrate incongruent cues (Campbell, 1988). They also have a tendency to lead to improper application of knowledge (Bonner, 1994). For example, in a study that directly links task complexity and errors, Clement (1999) found a negative relationship between accuracy in analysts' forecast and complexity of the task. Further, the real estate valuation literature suggests that complex valuation tasks have a high tendency to result in excessive variation in valuation opinions (Bretten and Wyatt, 2001; Hiironen et al., 2014). However, the relevant studies are largely descriptive and that the conceptualization of complex valuation tasks remains unclear.

Two different approaches are used to assess the extent of variation in valuations. First, past valuations submitted by private valuers for compensation purposes and the correspondent valuations of the same properties prepared by the Land Valuation Division (LVD), the official Government valuers are used to estimate the extent of variation. Secondly, a survey instrument is used to elicit the valuation of a hypothetical property from professional valuers in Accra, the capital city of Ghana to determine the variation among the valuation opinions submitted by the valuers. These levels of variations are markedly higher than have been reported in the literature for advanced markets, such as the U.K and U.S.A. Consistent with theory, it is also established that the extent of variation in valuations is influenced by complex valuation tasks.

The rest of the paper is organized as follows: the next section reviews the relevant literature. This is followed by an overview of valuation practice in Ghana to further contextualise the study. Thereafter, the complexity of valuation tasks is conceptualized, followed by a description of the data, methodology and discussion of results before conclusions for the study are drawn. 


\section{Review of the Relevant Literature}

The literature on property valuation errors in the developed world tend to cluster around studies in the UK, USA and Australia (Babawale and Ajayi, 2011). The enormous volumes of literature discussions relating to these countries were prompted predominantly by the collapse of the property and financial markets especially in the UK and USA in the 1980s and 1990s (Otegbulu and Babawale, 2011). Also, the studies on valuation errors have tended to focus on three main issues - valuation accuracy, variation and bias. Crosby (2000) draws a clear distinction between the three concepts of errors. According to the author, valuation accuracy is the ability of a valuation to correctly identify the target and this is informed by the basis of valuation. As such, where the basis of valuation is market value, accuracy will mean the ability of the valuation to correctly identify the sale price or rent of the property. In relevant studies, the target is often the subsequent price or rent of properties. The author notes that variation in valuations is the ability of two or more valuations to produce the same result using the same basis and at the same time. The focus of relevant studies is to measure the difference between the valuations. Conversely, valuation bias refers to over or under valuation in relation to a target - sale price or rent and could occur in the context of valuation accuracy or variation. From the standpoint of valuation accuracy, bias occurs when valuations consistently over or under value sale price or rent. This is also the case in the context of variation when a valuation or a valuer consistently over or under values another.

Although the pioneering work of Hager and Lord (1985) examined the extent of variation, the vast majority of subsequent studies have focussed on valuation accuracy by analyzing the correspondence between valuations and sales prices. The findings from Hager and Lord (1985) ignited an intense debate regarding the accuracy of valuation in the UK. Brown (1985) undertook two separate analyses relating to valuation accuracy and variation, and concluded that there was a correspondence between valuations and sale prices signifying high level of valuation accuracy. Furthermore, the study established that one firm's valuation was a good proxy for another also indicating limited variation among valuations. International Property Database (IPD) in collaboration with Driver Jones (IPD and Driver Jones (1988, 1990) also conducted two studies on valuation accuracy; the relationship between valuations and actual sale prices in 1988 and 1990. Both studies established high level of accuracy among valuations. 
Similar results have been documented in several studies such as Cullen (1994), Blundell and Ward (1999) Mokrane (2002). Findings from Mcallister (1995), and Matysiak and Wang (1995), however, appear to suggest that valuations are generally not good proxies of sale prices. A related study on valuation variation conducted by Adair et al. (1996) established that although the majority of valuations were close to the mean, a significant minority differed substantially. (Over $80 \%$ of all the valuations produced a variation from the mean of less than $20 \%$ ). Also, a perceptual study carried-out among valuers and their clients - lenders and investors by Bretten and Wyatt (2001) revealed that there was an agreement as to the notion that existence of variations in commercial property valuation for lending purposes was inevitable.

Studies in Australia and the USA also follow similar trend like those in the UK. In Australia, Newell and Kishore (1998) carried out accuracy study in Australia entailing 218 commercial properties over the period 1987-1996 and established an average overall difference between valuations and sale prices of $9 \%$ in absolute terms. After a further analysis adjusting for time lag, the study concluded that valuations are good proxies of sale prices. The USA study by Hansz and Diaz (2001), which sought to examine the effect of transaction price feedback on valuations using two hypothetical properties; an industrial property and a parcel of land in Pennsylvania and 40 valuers established variation in valuations of $10 \%$.

Apart from the above studies, there are other several studies on the developed world, such as Barkham and Geltner (1994), Hutchison et al. (1996), and Young and Graff (1999). However, it appears that studies on estimation of valuation errors tend to focus on the relationship between valuations and subsequent sale prices. Besides, there seem to be a lack of consensus among the studies. While the initial study by Hager and Lord was criticised among others for its small sample size, others, such as Brown (1985), IPD/Driver Jones (1988, 1990) and Cullen (1994), which reported high level of valuation accuracy are said to be fraught with methodological problems (Lizieri and Venmore-Rowland, 1991). Furthermore, Mcallister (1995) emphasising the methodological challenges pointed out that, the need to take account of the time lag between the date of valuation and sale since valuations and sales do not occur contemporaneously. Even Matysiak and Wang (1995), which addressed the statistical challenges including time lag, different markets and market conditions established that accuracy studies are inconclusive so was Mokrane (2002) who, as well established a number of valuation inconsistency problems. AddaeDapaah (2001), therefore, opines that the basis for addressing valuation accuracy is problematic 
and the focus of studies should rather be on variation. Also, the literature review shows that there appears to be limited or no recent studies into variation in valuations or valuation accuracy on the developed world, such as the UK, USA and Australia. The reasons for this situation are, however, unclear. Perhaps, relevant investigators perceive that variation in valuation and valuation accuracy issues in the developed world are settled or they are no longer fashionable.

Fewer studies, comparatively, have been carried out on estimation of property valuation errors in SSA. These have mostly taken place in Nigeria. Even so, it is a recent development (Babawale and Ajayi, 2011; Iroham et al., 2014). According to Babawale and Ajayi (2011) the first known documented study was carried out by Ogunba and Ajayi (1998), which was later followed by Ogunba (2004). The first study entailed the use of 30 valuers/ valuation firms. The study, which tasked the valuers based on a questionnaire survey to value two previously sold residential properties, reported results that signified low valuation accuracy. Babawale and Ajayi (2011) also examined the degree of accuracy achieved by Nigerian valuers by testing the hypothesis that there is no difference between mean score valuations produced by valuers and subsequent sale prices of residential properties. The study established that there was a statistically significant difference between valuations and subsequent transaction prices signifying low valuation accuracy. Several studies including Ayedun et al. (2011), Ogunba and Ajayi (1998), and Ogunba and Ajayi (2007) reported similar findings. Furthermore, a perceptual study by Adegoke et al. (2013) noted that valuers themselves do not think their valuations are accurate and reliable. More recent studies on the subject are Adegoke (2016) and Munshifwa et al. (2016). Whilst Adegoke (2016) examined the impact of valuation variance and inaccuracy on the commercial property market in Nigeria, Munshifwa et al. (2016) sought to analyse the variance in rating valuations conducted by public and private valuers in Zambia. The latter study found high variations in valuation and attributed them to data challenges, and the use of different methods and viewpoints although statute requires valuers to use the same methods and viewpoints. Nevertheless, it is important to point out that virtually all the studies on estimation of property valuation errors in SSA focused on valuation accuracy - valuation and sale price, and not variation.

\section{Valuation Practice in Ghana}


Anecdotal evidence shows that formal real estate valuation practice in Ghana is traceable to the colonial era. Real estate valuers like other built environment professionals, such as land surveyors, development planners, engineers and quantity surveyors were required to help the British colonial administration in its spatial development activities. The British colonial administration, therefore, instituted the framework for valuation practice in Ghana. Several legislations and policies that impinge on valuation practice were passed. For example, ordinances, such as the Waterworks Ordinance (1937), the Valuation of Premises Ordinance (1945), the Municipal Councils Ordinance (1953), the Local Government Ordinance (No. 29 of 1951) and the Valuation Bill (1955) were put in place to inform rating valuation in the country. Apart from valuers who acquired their training outside the country mostly in the UK, government also made arrangements for the training of valuation personnel locally. The Government Valuation School was, for example, established to train valuation technicians. Although private practice existed, most of the valuers worked for public institutions, such as the Railway Corporation, Public Works Department (PWD), the Lands Department, Housing Corporation and other parastatals.

In broad terms, valuation practice in the country at that time was guided by British standards. The valuers who received their training in the UK and became members of the Royal Institution of Chartered Surveyors (RICS) together with their counterparts from related disciplines, such as quantity and land surveying constituted the Ghana Branch of the RICS. However, in 1969 the Ghana Branch of the RICS at its Annual General Meeting (AGM)established the Ghana Institution of Surveyors (GhIS) (Sawyer, 1972). The membership of the new Institution comprised members of the RICS and the Institute of Quantity Surveyors, and those of the Licensed Surveyors Association who agreed to be incorporated into the class of Licentiates (Sawyer, 1972). The GhIS since then has been responsible for the regulation of surveying practice including valuation in Ghana for its members.

There are a number of challenges with the practice of valuation in Ghana. For example, there is a lack of national regulation on the practice of surveying in the country. This has resulted in proliferation of a lot of quack practitioners who often lack the requisite training and experience to practice valuation (Mahama and Antwi, 2006). As part of efforts to address this challenge, the GhIS have put together Survey Council and Real Estate Brokerage Bills. However, these bills are yet to be passed into laws. Another challenge is the unstable nature of the real estate markets in Ghana, which are characterised by rapid fluctuations in market prices, and quotation and payment of agreed prices in foreign currencies. Another major challenge to the practice of 
valuation in Ghana is the lack of adequate reliable property/market data (Gough and Yankson, 2000; Mahama and Antwi, 2006; Obeng-Odoom and Ameyaw, 2011). This challenge has often led to over-reliance on the use of the Cost Method of Valuation by valuers, and concerns over the standard of valuations produced in the country (Obeng-Odoom and Ameyaw, 2011). However, such concerns especially relating to valuation errors and variation in valuations are largely based on anecdotal evidence.

\section{The Theory of Task Complexity}

As noted in the introduction section of this paper, the growing body of literature on real estate valuation errors suggests that complex valuation tasks often culminate in excessive variation in valuation opinions. Nevertheless, it is unclear or there seem to be a lack of consensus on the definition of complex valuation task. Complex task is a very elusive concept to define. The concept has, thus, been studied in several disciplines, such as the information processing and decision-making, and the task and job design fields (Robinson, 2003, 2007). This research, however, hinges on insights from the integrative framework (theory) for task complexity developed by Campbell (1988). The use of the integrative framework stems from its overarching examination of the concept of task complexity and the insights it offers, in terms, of provision of an understanding into complex tasks as applied to real estate valuation errors.

The integrative framework is an amalgam of three distinct, but interrelated perspectives of a complex task. These are: a psychological experience of a task-doer; an interaction between task and person characteristics; and a function of objective task characteristics. Based on the stipulations of these perspectives, Campbell (1988) identifies three criteria for defining a complex task namely: information load, information diversity and the rate of information change. Thus, the framework holds that a task becomes more complex as and when its characteristics increase information load, information diversity or rate of information change. Before opening a discussion into the detailed propositions of the framework, it is important to acknowledge that although the afore-mentioned propositions connote an objective task function, the framework also notes that the proposition could be expressed in a subjective manner from the task doer standpoint. This could be done through examination of the cognitive demands a task places on a task doer. A complex task under this circumstance occurs where a task through its information load, diversity and rate of information change places high cognitive demands on the task doer. 
The above observation resonates with findings from Halvitigala et al. (2011), who examined the experiences of valuers in valuing market dominant and non-dominant standard lease structures, and compared the perceptions and approaches of New Zealand valuers when valuing gross and net leases; two standard lease types commonly utilised in the New Zealand commercial property market. The study used valuers from Auckland and Wellington. Auckland valuers were very much familiar with valuing net leases while the reverse was the case for Wellington valuers. The study established that Auckland valuers saw gross leases as very complicated compared to net leases. The reverse also was the case for Wellington signifying that unfamiliar valuation tasks place more cognitive demands on valuers. This is because the unfamiliar task meant that valuers had to obtain more information, develop new knowledge and analytical skills to make meaningful judgements. Thus, such valuation tasks could be considered complex from the standpoint of the valuers. Although different people have different cognitive abilities valuers not being an exception, valuers used in this study received the same training from (GhIS) and also operate within the same real estate market. This signifies that they were familiar with the subject market operations. They were, therefore, assumed to have the same cognitive abilities. Thus, task complexity from the subjective standpoint was not considered in this work.

Campbell (1988) identifies four characteristics that result in increase in information load, information diversity or rate of information change and can be regarded as contributing to task complexity. These include (a) the presence of multiple potential ways (paths) to arrive at desired end-state, (b) the presence of multiple desired outcomes (end-states) to be attained, (c) the presence of conflicting interdependence among paths to multiple outcomes, and (d) the presence of uncertain or probabilistic links among paths and outcomes. In the context of valuation assignments, these characteristics manifest themselves in the following ways. First, like many tasks, several paths (i.e. the different methods of valuation) exist in arriving at the desired end-state, which is the value estimate. The framework professes that task complexity increases where there are multiple pathways or potential pathways to execute the task compared to a situation where there is only a single pathway to the task execution. This is perceived to increase information load since information on each of the pathways need to be assembled to identify a suitable pathway to adopt. Nevertheless, the framework notes that a task becomes less complex where all multiple pathways or potential pathways to execute the task result in the same outcome. This implies that, the application of a particular pathway makes the other pathways redundant signifying a reduction in information load and processing. This further implies that a task becomes more 
complex if there are several pathways to execute the task and each of the pathways can result in a different outcome. This could be clearly conceptualised as valuation task, for example, determination of a market value of a property that could be undertaken by more than one valuation method as it is possible for each of the method to generate different outcomes.

Secondly, it is not uncommon for valuation assignment to require multiple outcomes, such as the case when a valuer is tasked to estimate the market value, rateable value or insurable value in the same assignment. Campbell (1988) argues that a task increases in complexity where the desired outcome increases. This proposition regards each of the desired outcomes as a task, which will require amount(s) of information and processing of such information. A combination of the different sets of information and their processing will, thus, make the task complex.

Conversely, the above proposition recognises that complexity evaporates when the desired outcomes are positively related meaning complexity increases where desired outcomes of a task are negatively related. This is often explained in terms of a task having both quality and quantity outcomes. As applied to real estate valuation, this could be perceived as a valuation assignment with several unrelated or negative desired outcomes. For example, a computer assisted mass valuation exercise, which seeks to undertake as many valuations with reduced cost implications and at the same time requiring detailed inspection and referencing of each of the properties.

The framework further holds that information load and processing requirements become very substantial if the link between potential task pathway activities and desired outcomes cannot be established with certainty. In such circumstances, the task becomes complex. In the context of valuation, this could manifest in a valuation problem or task where there is a lack of clear pathway either in theory or by practice guidelines to address. For example, the application of the replacement cost method in a valuation assignment of a newly constructed residential building on a leasehold land with unexpired term of three years located within an inarticulate market.

Apart from the foregoing propositions, the framework notes that complex tasks are often illstructured, ambiguous and difficult. However, these are borne out of basic task characteristics as espoused by the propositions. Consequently, the framework suggests that where a task contains one or more of the complexity characteristics it is likely to possess one or more of these three attributes. The reverse is not necessarily the case and that a task could bear all or any of the three attributes as a result of external factors signifying that task complexity should be assessed on task characteristics. 
Links have been drawn between task complexity and other concepts such as task performance, goal setting, strategy development and forecast accuracy (Wood, 1986, Campbell, 1988, Clement, 1999). In a study that directly links task complexity to errors, Clement (1999) found a negative relationship between accuracy in analysts' forecast and the complexity of the task. In the context of the valuation errors literature, evidence exists to suggest that the level of errors may be related to the complexity of the valuation assignment. For instance, Crosby (2000) points out that the margin of error applied by UK courts rises from the normal $10-15 \%$ range to $20 \%$ in cases where the valuation assignment is regarded as difficult. However, no study has directly tested empirically this proposition that difficult or complex valuations are more prone to errors.

\section{Conceptualizing Complex Valuation Assignments}

Although some tasks could satisfy all the complex task characteristics as prescribed by the integrative framework, the majority of tasks may not meet all the characteristics. This means that tasks should be evaluated based on the complex task characteristics prescribed by the framework to determine their levels or degree of complexity. In the discussion that follows, the complexity of valuation assignments of different property types are evaluated on the basis of the four task characteristics.

It is important to note that all the valuation assignments (tasks) under consideration were undertaken for the purpose of compensation for government's compulsory land acquisition for road alignments. The properties involved were of four main land utilisations (property types) namely: residential; retail/office; fuel service station and mixed land use ${ }^{1}$ (see the section on results). Consequently, the property types were used as the assignment (tasks) types. Also, complexity of the valuation assignments or tasks was determined by:

- the presence of the complexity characteristics in the task;

- whether the complexity characteristics are high (1), low (2) or very low (3) if they are present in the task;

- the total number of the complexity characteristics present in the tasks (see Table 1); and

- Also, the valuation complexity types were labelled as A-D (Table 1).

\section{INSERT TABLE 1 HERE}

\footnotetext{
${ }^{1} \mathrm{~A}$ combination of shop and residential land utilisation
} 
Table 1 shows that all the complexity characteristics were present in all the valuation tasks albeit in different levels. Further, the table shows that multiple valuation methods or pathways could be used to address all the valuation tasks. However, whilst the other three valuation tasks are typically limited to the three traditional methods of valuation namely: replacement cost, investment and market comparison methods, the valuation task relating to fuel service station usually requires more than the three traditional methods. Indeed, the subject valuation ordinarily requires methods, such as the profit method. This explains why the valuation complexity characteristic "A" was rated high for valuation relating to fuel service station and the ratings for other three tasks low.

The fundamental law (Ghana's 1992 Republican Constitution) on compensation for compulsory land and property acquisition in Ghana requires payment of prompt, adequate and fair compensation to expropriated owners. This often requires that valuations for compensation be carried-out in an expeditious manner especially given the weak and volatile nature of the Ghanaian economy, which is partly reflected in high inflation and the continuous depreciation of the $\mathrm{Cedi}^{2}$ against major currencies, such as the USA Dollar and the British Pound. Conversely, like with all valuations for compensations, valuers are supposed to undertake detailed and high quality valuations to prevent issues, such as unnecessary delays in reinstatement and litigations. All the valuation tasks were, thus, rated very low for the valuation task complexity characteristic "B". This was because two outcomes were expected: 1. expeditious assessment of market value for compensation purpose; and 2. detailed and high quality valuations of the subject properties. These outcomes were also negatively related and meant that valuation complexity characteristic "C" was present in all the valuation tasks.

The segmentation of real estate markets on the basis of property type implies a certain level of heterogeneity across the different property type categories. Within a given property type, however, the levels of diversity is expected to decrease and this is often a function of the extent of standardization of properties within a property type group. Generally, the application of the traditional methods of valuation requires some element of comparison of properties. In situations where the properties within a given type are non-standardized, greater levels of uncertainty will be introduced in the process of making comparisons to establish the value of the property. As a

\footnotetext{
2 The Ghanaian Currency
} 
result, information processing requirements for such tasks will increase substantially (Campbell, 1988) and lead to higher levels of complexity. Thus, one should expect higher levels of complexity for valuation assignments involving a property belonging to property type that exhibits greater heterogeneity arising from the lack of standardization. In contrast to property markets of western economies, the residential property market in Ghana is characterised by lack of standardization in residential units. This is largely due to the fact that housing delivery is carried out by individual households, often through informal channels. This allows for customization of the units to suit the idiosyncratic tastes and preferences of households. Fuel stations also exhibit a considerable level of heterogeneity albeit for economic rather than physical reasons. The economic characteristics of two identical fuel stations can be very different and makes comparisons difficult. Shops of the kind under consideration, on the other hand, are very similar in their physical attributes and exhibit minimal differences in the economic activities they support. As a result, residential property and fuel station are ranked highest on task characteristic (D) whereas shops are ranked lowest.

From the standpoint of the integrative framework, therefore, it could be safe to state that valuation of the fuel service station was somewhat ill-structured, ambiguous and difficult. This is in tandem with common knowledge in the subject market that valuation of fuel service station in Ghana is quite difficult and ambiguous. This is followed by residential property type with shops expected to show the lowest complexity. Consequently, the study hypothesizes as follows:

All things being equal valuation assignments that exhibit greater levels of task complexity are prone to more errors

Consistent with the discussions and hypothesis stated above, valuation of fuel stations are expected to be associated with the greatest level of variation. Specifically, the relationships between the variations among the various property types are outlined as follows:

$$
C O V_{\text {fuelstation }}>C O V_{\text {residentid }}>C O V_{\text {mixed }}>C O V_{\text {shop }}
$$

Where $\mathrm{COV}_{\text {fuel station, }} \mathrm{COV}_{\text {residential }}, \mathrm{COV}_{\text {mixed }}$ and $\mathrm{COV}_{\text {shop }}$ are the coefficient of variation for fuel stations, residential, mixed use and shop property types respectively.

\section{Data}


Two approaches; examination of institutional valuation databases and questionnaire survey of real estate valuers, were employed to obtain the data for this study. Estimation of the extent of variation in valuations requires two or more valuations conducted on same properties for the same purpose at or around the same period of time (Brown, 1992). The first strategy was, therefore, primarily employed to examine databases of the main property valuation institutions in Accra to obtain two or more valuations conducted on the same properties for the same purpose at or around the same period of time. The LVD of the Lands Commission provided access to its database for this purpose. The LVD is the main public valuation entity in Ghana. The Division conducts all forms of valuations for government and public agencies in the country. It also undertakes valuation consultancies and accepts into its database valuations undertaken by other public agencies and private valuers/valuation firms especially on cases relating to compensation payments for government acquisitions. Such cases often rely on valuations produced by the Division and the expropriated owners' valuers as bases for negotiations to determine the compensation payable. The sample used covers a period of $2009-2014$ and consists of two sets of valuation opinions in respect of 98 government acquisitions across two different regions of Ghana; Greater Accra and Western Regions. Ordinarily, the data sets ought to have been more recent as to cover the period up to 2016 . However, such data were non-existent as they were dependent on government's implementation of compulsory land acquisition schemes, and as at the time of the study, there was no evidence of acquisitions for the period under reference. In addition to the opinion of value, the dataset also included property specific information such as location; property type; interest in the property and the unexpired term; size of the property; registration status; purpose of valuation; basis of valuation; dates on which the valuations were conducted; and the method(s)of valuation used. The final sample consisted of 196 valuation opinions on 98 properties with the common purpose of determining the market value for compensation purposes. It is also important to state that the method of valuation for about $95 \%$ of all the valuations was the replacement cost method.

Further, although both government (LVD) and the private valuers are supposed to produce professional and ethical valuations in accordance with their professional standard requirements, in practice they could be influenced by their clients' interests. This could result in valuers anchoring their valuation opinions to the expectations of their clients. In this case, for example, the LVD valuers might have provided low valuation opinions compared to high valuation figures from the private valuers for their clients, which could lead to excessive variation. Indeed, recent real estate 
behavioural studies (Levy and Schuck, 1999, 2005; Amidu and Aluko, 2007; Chen and Yu, 2009; Crosby et al., 2010; Iroham et al., 2014; Nwuba et al., 2015; Bellman and Öhman, 2016) have brought to the fore that client influence is pervasive in valuation practice and this may lead to anchoring in valuation. Although it is probable, the evidence of client influence on valuations in Ghana is unclear and, in particular, those relating to compensation valuations. Besides, anecdotal evidence suggests that private valuers clients could also influence LVD (government) valuers. It cannot, therefore, be taken as a forgone conclusion right from the outset that due to client influence two extreme valuation opinions are imminent. Nevertheless, it is partly because of the somewhat dated nature of the archival datasets and the perceived clients influence on the valuation outcomes that the survey of real estate valuers was carried-out as a second strategy to complement the first method.

As noted above, the second strategy involves the use of a questionnaire survey to elicit from professional valuers an opinion of value for a specified property under similar conditions at or around the same time. The questionnaire targeted real estate valuers who are members of the GhIS. It requested the valuers to undertake market valuation of a hypothetical property as at a particular date based on the same set of instructions. The property was a leasehold single storey 3-bedroom house with an unexpired term of 10 years sited on 0.093 hectare land located within the State Housing Company Neighbourhood along the Liberation Road, Airport Residential Area, Accra, a commonly known area. All the property details were given to the respondents. These included the specific location of the property, its construction details, fixtures and fittings, external works, access to services, neighbourhood characteristics, total floor area, sketch ground floor and location plans, title and planning/building permit status and ground rent reserved. Also, information on the method employed by the respondents to undertake the valuation and why they employed the method was obtained.

The questionnaires were self-administered. Thus, the questionnaires were personally delivered to respondents and completed survey picked up by researcher(s). Prior to the administration, a pretesting of the questionnaire was undertaken to ensure that it passed the face and content validities test. A total of 110 questionnaires were administered to the respondents. The respondents were selected based on purposive and snow ball sampling techniques. These sampling techniques were employed due to a lack of reliable sample frame. Although the GhIS provide a yearly list of valuers in good standing in Ghana, there is no such list specifically for 
valuers in Accra. Also, the lists do not often have the address and location of valuers. Accordingly, probability sampling could not be undertaken. The selected sampling approaches were, therefore, the most practical and suitable means by which the required data could be procured to deliver the research.

Based on the authors' knowledge of practicing valuers in Accra, information provided by the GhIS and some senior officials of the Institution, the respondents were initially contacted by phone and e-mails to inform them of the survey and to enquire about their readiness to participate. Subsequently, the researcher(s) visited and discussed the survey with the respondents, and administered the questionnaires to them. Also, dates for collection of the completed questionnaires were agreed upon with the respondents. Prior to the initial contact with the respondents, however, the GhIS informed its members of the survey and encouraged them to participate in it, as much as possible.

\section{Methodology}

Similar to studies, such as Hansz and Diaz (2001), the extent of variation is assessed using the coefficient of variation of the value estimates. For the sets of valuation opinions that were obtained from the database of the LVD, the coefficient of variation is first calculated for each pair of valuations on the same property after which the mean of the series of coefficient of variations was computed as follows:

$$
\mathrm{CoV}=\frac{\mathrm{SD}}{-\bar{x}}
$$

Equation 1

Where:

$\mathrm{CoV}=$ Coefficient of variation for each pair of valuations;

$\mathrm{SD}=$ Standard deviation of each pair of valuations; and

$x=\quad$ The mean of each pair of valuations.

The standard deviations and the means were also assessed respectively as follows: 
$\mathrm{SD}=\sqrt{\frac{\sum_{\mathrm{i}=1}^{\mathrm{n}}\left(x_{i}-\bar{x}\right)^{2}}{n-1}}$

$\bar{x}=\frac{\sum x_{i}}{n}$
Equation 2

Equation 3

Where:

$\mathrm{SD}=$ As previously defined;

$x=\quad$ As previously defined;

$x_{i} \ldots \ldots x_{n}=$ Estimated market values by both the LVD and private valuation practitioners; and

$n=\quad$ The number of valuations for each property.

The mean of the coefficient of variations was assessed as follows:

$$
\bar{x}_{\mathrm{CoV}}=\frac{\sum x_{i \mathrm{Cov}}}{n_{\mathrm{Cov}}}
$$

Equation 4

Where:

$x_{\mathrm{CoV}}=$ Mean coefficient of variation;

$x_{i C o v}=$ The coefficients of variation of each pair of valuations; and

$n_{\text {Cov }}=$ The total number of the coefficient of variations (sample size).

The extent of variation in the market valuations obtained from the questionnaire survey was estimated by coefficient of variation and percentage median deviation of the valuations. Thus, the coefficient of variation of all the reported market values was estimated. The percentage median deviation was used because evaluation of the distribution of the reported market values was not 
normal based on both Levene and Simonov Kolmogorov tests. The median was, therefore, more representative of the distribution of the values than the mean (Field, 2005). The use of the percentage median variation to report the extent of variation is similar to the study carried-out by Adair et al. (1996), which used the percentage mean deviation to do so.

Using absolute values and ignoring negative signs, the percentage median deviation of each reported market value from the median market value was assessed as follows:

$$
P M D_{i}=\left|\frac{x_{i}-M D}{M D}\right| \times 100
$$

Equation 5

Where:

$$
\begin{aligned}
& P M D_{i}=\quad \begin{array}{l}
\text { Percentage median deviation of each reported market value from the } \\
\text { median/Mean market value }
\end{array} \\
& x_{i}=\quad \text { Each reported market value } \\
& M D=\quad \text { Median/Mean market value }
\end{aligned}
$$

To test the hypothesis that the extent of variation is influenced by the complexity of the task and using the different property types as indicators of task complexity, a one-way analysis of variance (ANOVA) was estimated. More specifically, it tests the null hypothesis that the mean coefficients of variation for the different property types are equal. Thus;

$$
H_{o}=\mu_{1}=\mu_{2}=\mu_{3 .}=\ldots . .=\mu_{n}
$$

Where $\mu=$ mean coefficient of variation for a property type and $n=$ number of groups.

To determine how the mean coefficient of variation for specific property types differed from each other, Tukey HSD post-hoc test is used. 


\section{Results}

\section{Archival Data}

A total of 196 valuations (a pair of 98 valuations) were obtained from the LVD. As stated previously, each data set consisted of 2 valuations; one from the LVD and the other from a private valuer or valuation firm. The valuations were conducted between 2009 and 2014. The entire valuations were conducted for the purpose of compensation for government's compulsory acquisition. Market value constituted the basis of all the valuations. Almost all the valuations were conducted both from the standpoints of the LVD and private practitioners with the replacement cost method of valuation (about $95 \%$ of the valuations). However, there were few cases where other methods of valuation were employed (5\%).

The subject matter of the valuations comprised a washing bay; and single storey, two storey and three storey structures both completed and uncompleted. With the exception of $17.34 \%$ of the properties whose land sizes were not available, the land sizes for the properties range between 0.01 and 0.65 acres. The properties were located in two regions; the Greater Accra and the Western Regions of the Republic of Ghana. However, most of them were in the Greater Accra Region. The interests subsisting in the properties comprised customary freehold and estates of freehold and leaseholds although interests in a significant number of the properties were not available. The unexpired term for most of the leasehold interests were also not available. It was ascertained that where ownership of the land on which the improvements (properties) were sited was in dispute, the valuations were restricted to the improvements. This, coupled with nonavailability of some of the information on the properties' details may be a probable reason for the reliance on the replacement cost of valuation method to undertake most of the valuations. This further emphasises the paucity of property/market data problem in Ghana for good valuation practice as identified by the relevant literature. For the purpose of the analyses, the properties were categorised into four main property types namely: office/retail shop; residential; fuel service station; and mixed-land use.

The majority of the observations were valuations on office/retail shop properties compared to fuel service station, which recorded the lowest observations. A little over 54\% were valuations on office/retail shop properties. This was followed by the valuations on residential properties, which constituted $29.59 \%$ and then mixed land use and fuel service station, which formed $9.18 \%$ and $7.14 \%$ of the valuations respectively (Table 2 ). The distribution of the sample by property type 
does not correspond with the structure of the real estate market in Ghana, which is dominated by residential properties. Nevertheless, it is quite understandable given that the valuations were for compensation claims on government compulsory acquisitions for existing road widening and alignment. This means that most of the expropriated properties were located along existing roads and the majority of such properties in the case study country are retail shops particularly the informal ones, and office premises.

Table 2 also reports the results of the extent of variation in the valuations based on the estimated coefficients of variation for the entire sample and by property type. The results show that the variations in the total observations ranged from a minimum of $0.014(1.4 \%)$ to a maximum of 1.304 (130.4\%). Overall, the results show that valuations in the sample had, on average, a coefficient of variation of $0.336(33.6 \%)$ whereas the median coefficient of variation was 0.237 $(23.7 \%)$. Further breakdown of the coefficient of variation by property type demonstrates that the extent of variation in the valuations on fuel service station recorded the highest level of variation (68.2\%). This was followed by variation in valuations on residential properties $(44.8 \%)$, mixed land use (36.9\%) and retail/office (22.3\%) in that order (Table 2). While the high level of variation in the valuations on fuel service station could possibly support the assertion that complex properties are more prone to have high variations in their valuations (Bretten and Wyatt, 2001) given that this property type was the most complex, the extent of variation in the valuations on the other property types, in particular residential was striking.

Ordinarily residential properties are expected to be simple compared to office/shop and mixed land uses or properties. Consequently, the high variation in the valuations on the residential properties compared to those of the mixed land use and retail/office properties was least expected. This perhaps could be explained by the varying nature of the residential properties that constituted the subject matter of the valuations. In fact, unlike countries, such as the UK and the USA where residential properties are often standardized, residential properties in the case study country especially those outside the emerging gated communities come in various forms, designs and sizes. Another possible reason for the low variation in valuations on the office/retail shop properties compared to those of the residential properties and the mixed land utilisation could be that most of the office/retail properties were the small simple informal type developments. This would have meant that the properties were much simpler compared to the other property types. 


\section{INSERT TABLE 2 HERE}

In broad terms, the results reflect wide variation in valuations compared to the often accepted margin of error of between $\pm 5 \%$ and $\pm 15 \%$ and in exceptional case of residual valuations up to $\pm 20 \%$ for UK valuations (Crosby, 2000). A plausible reason for the wide variation in the valuations could be the probable positions of the LVD and private valuation practitioners in compensation claim transactions as discussed previously. Whereas it is natural for the LVD to seek to reduce the compensation claims paid by government, the private practitioners will want enhanced claims for their clients. This could result in two extreme value estimates and hence wide variation in the estimates. This result corroborates findings from Munshifwa et al. (2016). However, unlike the probable reason attributed to the variation by this study, Munshifwa et al. (2016) note that besides information factors, the major causes for variation are the adoption of different methods and viewpoints although statute requires valuers to adopt the same methods and viewpoints in relevant cases.

To ascertain whether or not the difference between the extent of variations in valuations on the property types was statistically significant (to test the hypothesis that property type had an effect on the extent of variations in the valuations, a one-way independent between groups analysis of variance (ANOVA) was undertaken to compare the means of the coefficients of variation of the property types. Further, a post-hoc multiple comparison of the means of the coefficients of variation by property type based on Tukey HSD was undertaken to evaluate the nature of the difference of the extent of variation in valuations among the property types. Results from both analyses are reported in Tables 3 and 4 respectively. Prior to undertaking the ANOVA, both the assumptions of normality and homogeneity of variance were evaluated to ensure that they all satisfy the requirements of parametric test.

The results established that property type has a statistically significant effect on the extent of variation within the valuations, $(F(3,97)=10.009, P=0.00)$. Results from the post-hoc analyses show that the extent of variation in valuations on the retail/office properties was lower than all the other three property types except for the mixed land use, which showed no statistically significant difference. Also, the extent of variation in valuations in the residential properties was lower when compared to that of the fuel service station, and higher when compared to that of mixed land use, but both were not statistically significant. Further, the extent of variation in the 
valuations on fuel service station was significantly higher compared to that of mixed land use at the $10 \%$ level of significance. Substantively, the results support the notion that more complex valuation assignments are likely to be more prone to errors. This is consistent with theoretical predictions and findings in Clement (1999), which found accuracy of analysts' forecasts to be negatively associated with the complexity of the task.

INSERT TABLES 3 \& 4 HERE

\section{Survey Data}

Seventy (70) out of a total of 110 questionnaires administered to the real estate valuers were received. This constituted $63.64 \%$ of the questionnaires that were administered. This is more than the response rate recorded from comparable studies, such as Adair et al. (1996) (56\%). The extent of variation in the valuations obtained from the survey of real estate valuers was estimated by Equations 1 and 5. Tables 5 and 6 summarise the results on the extent of variation in the market value estimates received from the respondents on the 3-bedroom residential property that constituted the subject matter of the valuations. The results corroborate findings from the analyses of the archival data on the potential existence of wide variations in valuations produced in Ghana. However, the variation in the valuations observed from the survey data $(63 \%)$ was higher than that of the archival data. Also, the results show that only $2.86 \%, 8.57 \%$ and $14.29 \%$ of the valuations fell with $\pm 5 \%, 10 \%$ and $20 \%$ of the median for the reported value estimates respectively (Table 6). Further, these results show a much higher variation compared to Adair et al. (1996) in the UK, which established that the majority (80\%) of the sampled valuations $(n=446)$ produced a variation from the mean of $<20 \%$ and Hansz and Diaz $(2001)$ in the USA, which produced a coefficient of variation of $0.098(9.8 \%)$.

INSERT TABLES 5 \& 6 HERE 
Two main plausible reasons could be attributed to the high level of variability in the value estimates that were reported by the respondents. First, the subject matter of the valuations; a leasehold interest in a residential property with an unexpired term of 10 years may have appeared quite complex to the respondents. This is because in practice valuations of such properties are often valued as 50-year leases based on the assumption that government will renew the lease although renewal is usually undertaken at a substantial cost, and it is not guaranteed. Second, the use of different methods of valuation to arrive at market value estimates could have accounted for the high variability in the valuations. The results show that 8 different approaches (sales comparison (35.71\%), replacement cost $(38.57 \%)$, investment $(15.71 \%)$, sales comparison and replacement cost $(4.29 \%)$, sales comparison and replacement cost and investment $(2.86 \%)$, sales comparison and investment $(1.4 \%)$, investment and replacement cost $(1.4 \%))$ were used by the respondents to produce the market value estimates. While this may reflect inadequate standardisation in valuation practice, which could be corroborated by the numerous reasons reported by the respondents for the choice of a particular approach, it also mirrors the property/market data challenge to valuation practitioners.

The study further investigated whether the choice of method has any effect on high level of variation. This was done by disaggregating the variation by method of valuation used. In general, the choice of valuation method should depend on the nature of the property, the purpose of valuation and the availability of data. In as much as more than one method can be used for any particular valuation exercise, there is usually the most suitable method in many cases. For instance, a valuation of an office complex encumbered by leases would require the use of the income approach as the most suitable even though other methods, such as the cost or even the sales comparison may also be used. Thus, it is possible for a valuer to adopt a less than appropriate method, which can result in valuation errors. Given that the subject matter of the valuations was located in an articulate local market with substantial volumes of transactions, and based on valuation theory, the market approach (sales comparison) should have been the preferred method of valuation. However, as indicated above different methods were adopted by the respondents. Table 7 presents the variation by valuation method. It is striking that the level of variation among valuers who adopted the sales comparison approach is the lowest followed by respondents who adopted more than one method.

Almost all those who adopted more than one method used the sales comparison approach. The fact that valuations based on the sales comparison approach, which is considered as the most 
appropriate method, produced the least variation highlights the need for valuers to carefully consider the methods they adopt as this is likely to affect the extent of errors their valuations may carry. Coincidentally, the method with the highest level of variation is the cost approach, arguably the least appropriate method given the nature of the property and other existing circumstances. Further, regression analysis is carried out on the absolute percentage variation to the methods of valuation. The focus was only on the cases where only one method was adopted to sharpen the analysis. The results, which are reported in Table 8, show that variation among valuers who use the cost approach is statistically significantly different at $5 \%$ level of significance from that of valuation opinions based on the sales comparison confirming the previous results. However, the difference between the percentage variations for valuations carried out using the sales comparison and the income approach, even though positive, is not statistically different from zero.

\section{INSERT TABLES 7 \&8 HERE}

The overall results from both the archival and survey of real estate valuers data show that the levels of variations in valuations are markedly higher than have been reported in the literature for advanced markets, such as the U.K and U.S.A. The relevant literature (Levy and Schuck, 2005; Babawale and Omirin, 2012; Hiironen et al., 2014; Iroham et al., 2014) and the preceding discussions show that behavioural factors, such as client influence and anchoring; complex nature of properties; data problems; the unstable nature of the property market; application of inappropriate valuation methods; and lack of standardization in valuation practice, are the major factors responsible for variation in valuations. Although this study demonstrates that complex valuation assignments lead to variations in valuations, the marked difference between the extent of variation in valuations in Ghana and those reported in advanced markets, in the main, could be attributed to inadequate quality and reliable market data, unstable property markets, the use of inappropriate valuation methods and lack of standardization in valuation practice. Inadequate quality and reliable market data has adequately been discussed in the literature as the main bane for valuation practice in Ghana (Mahama and Antwi, 2006; Baffour Awuah et al. forthcoming). This is compounded by the general unstable and inarticulate nature of property market in the country, which is partly rooted in the weak and volatile nature of the Ghanaian economy and often reflected in high inflation and the quotation of prices in certain segments of the market in major currencies, such as the USA Dollar and the British Pound. In the face of these 
imperatives, therefore, valuers are sometimes compelled to combine and improvise methodologies, which partly account for lack of standardization in practice and ultimately errors in valuations, such as excessive variation in valuations.

\section{Conclusion}

This study examined the extent of variations among valuations produced by professional valuers in Ghana in response to the growing concerns about the standards of valuation practice within the country and the SSA region generally. The study also examined the effect of complex valuation tasks on the levels of variation in valuations. Unlike several previous studies, the issue is addressed by relying on two different approaches enabling the drawing of more robust inferences. Using well established methodologies, the study found high levels of variations in valuation opinions of $33.6 \%$ and $63 \%$ for the archival data and survey data respectively among professional valuers in Ghana. These levels of variations are substantially higher than have been reported in the literature for advanced markets suggesting that the concerns of valuation errors in Ghana and across SSA may be well grounded. Further, consistent with theory, the variations in the valuation opinions may be more pronounced in comparatively more complex valuation assignments.

These findings have several implications. First, given the central role valuation plays in the decisions of several agents in both the private and public sectors, the existence of errors in valuations can be a recipe for severe distortions in the property market with potential dire consequences for the economy especially the financial system. Secondly, there is a greater likelihood that users of valuation opinions would lose confidence in valuers if wide variations become pervasive. This will heighten market uncertainty, increase transaction costs and impede the development of the real estate sector. Thirdly, the findings highlight the need for standardization of practice and the intensification of continuous professional development programs with the view to achieving convergence on key matters, such as the choice of appropriate methods of valuation.

Although previous real estate valuation studies both in the developed and the developing worlds had reported that complex properties or valuation assignments are more prone to errors, none of them was able to conceptualize complex valuation assignments and further test the authenticity or otherwise of the assertion based on empirical data. Based on the task complexity theory, this study conceptualized a complex valuation assignment and tested whether or not complex valuation tasks lead to valuation errors based on empirical data. Consistent with theory, the study found substantially higher levels of variation for the valuation of fuel stations, which were 
hypothesized to exhibit the greatest levels of task complexity than other property types, such as shops and offices. This finding, therefore, makes a significant contribution to knowledge in terms of expanding and extending the existing literature. Further, task complexity has been conceptualized along a number of dimensions in other disciplines in the literature. However, it has generally been difficult to objectively discriminate among different tasks on the basis of complexity to allow for empirical examination of the various effects of task complexity. The use of the task complexity theory to examine the effect task complexity has on the performance of valuers in providing opinions of value by exploiting the heterogeneous nature of real estate enabled clear articulation and definition of a complex valuation task, as well as its ingredients. This is particularly useful to valuers and most importantly regulatory bodies, such as the GhIS, RICS and the Appraisal Institute in terms of understanding and identifying complex valuation assignments. This in turn could lead to the development of appropriate standards and guidelines for undertaking such assignments, as well as issues, such as corresponding scale of fees and effective and efficient valuation services to support the operation of property and financial markets. Last but not the least, the study's provision of evidence of the link between complex valuation task and valuation errors highlights the need for valuers to exercise extra care and tact in carrying-out complex valuation assignments, and the valuation profession to improve and develop new suitable standards for such complex assignments. References

Adair, A., Hutchison, N., MacGregor, B., McGreal, S. and Nanthakumaran, N. (1996). An analysis of valuation variation in the UK commercial property market. Journal of Property Valuation and Investment, 14(5), pp. 34- 47.

Addae-Dapaah, K. (2001). Valuation accuracy - a problematic enquiry. Paper presented at the $8^{\text {th }}$ European Real Estate society Conference, 26-29 June, Alicante.

Adegoke, O.J., Olaleye, A. and Oloyede, S.A. (2013). A study of valuation clients' perception mortgage valuation reliability. African Journal of Environmental Science and Technology, $7(7), 585-590$.

Adegoke, O.J. (2016). Effects of valuation variance and inaccuracy on Nigerian commercial property market. An empirical study. Journal of Property Investment and Finance, 34(3), pp. 276-292.

Amidu, A.R. and Aluko, B.T. (2007). Client influence in residential property valuations: an empirical evidence. Property Management, 25(5), pp. 447-461.

Ayedun, C.A., Ogunba, O.A., Oloyede, S.A. (2011). Empirical verification of the accuracy valuation estimates emanating from Nigerian valuers: a case study of Lagos Metropolis. International Journal of Marketing Studies, 3(4), pp. 117-129.

Babawale, G.K. and Ajayi, C.A. (2011). Variance in residential property valuation in Lagos, Nigeria. Property Management, 29(3), pp. 222-237.

Babawale, G.K. and Omirin, M. (2012). An assessment of the relative impact of factors influencing inaccuracy in valuation. International Journal of Housing Markets and Analysis, 5(2), pp. 145-160.Baffour Awuah, K.G., Hammond, F.N., Lamond, J.E. and Booth, C.A. (2014). Impact of land use planning on real estate investment return in a developing world context: A case study of Ghana", in: Squires, G. and Heurkens, E. (Eds.) International Approaches to Real Estate Development, London, Routledge.

Baffour Awuah, K.G., Gyamfi-Yeboah, F., Proverbs, D. and Lamond, J. (Forthcoming). Sources and reliability of property market information for property valuation practice in Ghana. Property management. 
Barkham, R. and Geltner, D. (1994). Unsmoothing British valuation-based returns without assuming an efficient market. Journal of Property Research, 11(2), pp. 81-95.

Bellman, L. and Öhman, P. (2016). Authorised property appraisers' perceptions of commercial property valuation. Journal of Property Investment and Finance, 34(3), pp. 225-248.

Blundell, G.F. and Ward, C.W.R. (1999). The accuracy of valuations - expectations and reality. Working paper, Department of Land Management, University of Reading, Reading.

Bonner, S.E. (1994). A model of the effect of audit task complexity. Accounting, Organizations and Society, 19(3), pp 213-34

Bretten, J. and Wyatt, P. (2001). Variance in commercial property valuations for lending purposes: An empirical study. Journal of Property Investment and Finance, 19(3), pp. 267 282.

Brown, G. (1985). Property investment and performance measurement: A reply. Journal of Valuation, 4(1), pp. 33-44.

Brown, G.R. (1992). Valuation accuracy: Developing the economic issues. Journal of Property Research, 9(3), pp. 199-207.

Campbell, D.J (1988). Task complexity: A review and analysis. Academy of Management Review, V13(1), pp 40-52.

Chen, F. and Yu, S. (2009). Client influence on valuation: does language matter? A comparative analysis between Taiwan and Singapore. Journal of Property Investment and Finance, 27(1), pp. 25-41.

Clement, B.M. (1999). Analyst forecast accuracy: Do ability, resources, and portfolio complexity matter? Journal of Accounting and Economics, 27(3), pp. 285-303

Crosby, N. (2000). Valuation, accuracy, variation and bias in the context of standards and expectations. Journal of Property Investment and Finance, 18(2), pp. 130-161.

Crosby, N., Lizieri, C. and McAllister, P. (2010). Means, motive and opportunity? Disentangling client influence on performance measurement appraisals, Journal of Property Research. 27(2), pp. 181-201.

Cullen, I. (1994). The accuracy of valuations revisited. London: the Royal Institution of Chartered Surveyors, pp. 91-101.

Drivers Jonas/IPD (1988). The Variance in Valuations. London: Drivers Jonas/Investment Property Databank.

Drivers Jonas/IPD (1990). The Variance in Valuations: 1990 Update. London: Drivers Jonas/Investment Property Databank.

Field, A. (2005) Discovering Statistics Using SPSS (2nd Edn.). London: Sage Publications.

FTSE Global Markets (2015) Sub-Saharan African real estate: a growing asset class? Online at: http://www.ftseglobalmarkets.com/issues/issue-80-january-february-2015/sub-saharanafrican-real-estate-a-growing-asset-class.html [Accessed: August, 2015].

Gough, K.V. and Yankson, P.W.K. (2000). Land Markets in African Cities: The Case of Peri-urban Accra, Ghana. Urban Studies 3(13), 2485 - 2500.

Hager, D. and Lord, D. (1985). The Property Market, Property Valuations and Property Performance Measurement. London, Institute of Actuaries.

Hansz, J.A. and Diaz, J. (2001). Valuation bias in commercial appraisal: a transaction price feedback experiment. Real Estate Economics, Vol. 29(4), pp. 553-565.

Halvitigala, D., Murphy, L. and Levy, D. (2011). Dominant and non-dominant lease structures and their effect on place-based valuation practices. Journal of Property Investment and Finance, vol. 29 , no. 6, pp. 595-611. 
Hiironen, J. Ronen, K., Niukkanen, J.O. and Ari Laitala, A. (2014). Margin of Error' in Property Valuations - is There a Need for Safety Margins in Compulsory Acquisitions? Paper presented at the FIG Congress 2014, Kuala Lumpur, Malaysia $16-21$ June.

Hutchison, N., MacGregor, B., Nanthakumaran, N., Adair, A. and McGreal, S. (1996). Variations in the Capital Valuations of UK Commercial Property. Research report, London, The Royal Institution of Chartered Surveyors.

IMF (2015). Regional Economic Outlook: Sub-Saharan Africa - Navigating Headwinds. World Economic and Financial Surveys.

Iroham, C.O., Ogunba, O.A. and Oloyede, S.A. (2014). Effect of principal heuristics on accuracy of property valuation in Nigeria. Journal of Land and Rural Studies, 2(1), pp. 89-1 11.

JLL (2014). Real Estate Transparency improves in Sub-Saharan Africa. JLL.

Levy, D.S. and Schuck, E.J. (1999). The influence of clients on valuation. Journal of Property Investment and Finance, 17(4), pp. 380-400.

Levy, D. and Schuck, E. (2005). The influence of clients on valuations: the clients' perspective. Journal of Property Investment and Finance, 23(2), pp. 182-201.

Lizieri, C. and Venmore-Rowland, P. (1991). Valuation accuracy: A contribution to the debate. Journal of Property Research, 8(2), pp. 115-122.

Lorenz, D. and LÜtzkendorf, T. (2008). Sustainability in property valuation: Theory and practice., Journal of Property Investment \& Finance, Vol. 26(6), pp. 482-521.

Mahama, C. and Antwi, A. (2006). Land and property markets in Ghana. London: RICS.

Matysiak, G. and Wang, P. (1995). Commercial property market prices and valuations: Analysing the correspondence. Journal of Property Research, 12(3), pp. 181-202.

McAllister, P. (1995). Valuation accuracy: A contribution to the debate. Journal of Property Research, 12(3), pp. 203-216.

Mokrane, M. (2002). Valuations - standards, accuracy, consistency. Paper presented at IPD European Property Strategies Conference at Wiesbaden.

Munshifwa, E.K., Jain, N., Kaunda, B.S., Masiba, L., Lungu, J., Chunda-Mwango., N., Mushinge, A., and Ngoma, W. (2016). Variances in rateable values in rating practice in Zambia: the role of mental models in value assessment. Pacific Rim Property Research Journal, 22 (2), pp. 181-201.

Newell, G. and Kishore, R. (1998). The Accuracy of Commercial Property Valuations. Paper presented at the $4^{\text {th }}$ Pacific Rim Real Estate Society Conference, January, Perth.

Nwuba, C.C., Egwuatu, U.S. and Salawu, B.M. (2015). Clients' means of influence on mortgage valuation in Nigeria. Property Management, 33(4), pp. 367-385.

Obeng-Odoom, F. and Ameyaw, S. (2011). The state of surveying profession in Africa: A Ghanaian perspective. Property Management, 29(3), pp. 262-284.

Ogunba, O. A and Ajayi, C.A (1998). An assessment of the accuracy of valuations in the residential property market of Lagos. The Estate Surveyor and Valver, 21 (2), pp.19-23.

Ogunba, O.A. (2004). The demand for accuracy in valuations: the case of Nigeria. Proceedings of the International Symposium on Globalization and Construction, Bangkok, Thailand.

Ogunba, O.A. and Ajayi, C.A. (2007). The response of Nigerian valuers to increasing sophistication in investors' requirements. Journal of Property Investment and Finance, 25(1), pp. 43-61. 
Otegbulu, A. and Babawale, G.K. (2011). Valuers' perception of potential sources of inaccuracy in plant and machinery valuation in Nigeria. Property Management, 29(3), pp. 238-261.

PWC (2012). An African perspective: Valuation methodology survey (6 th Edn.). Johannesburg: PWC.

Robinson, P. (2003). The cognition hypothesis, task design, and adult task-based language learning. Second Language Studies, 21(2), pp. 45-105.

Robinson, P. (2007). Task complexity, theory of mind, and intentional reasoning: Effects on L2 speech production, interaction, uptake and perceptions of task difficulty. IRAL 45, pp. 193-213.

Sawyer, H.M. (1972). Presidential speech at the inauguration of the Ghana Institution of Surveyors. The Journal of the Ghana Institution of Surveyors Vol. II (1), pp. 19-21.

Viruly, F. and Hopkins, N. (2014). Unleashing Sub-Saharan Africa Property Markets. London: RICS

Wood. R.E. (1986). Task complexity: Definition of the construct. Organization Behaviour and Decision Processes, 37(1), pp. 60-82.

Young, M. and Graff, R. (1999). Measuring random appraisal error in commercial real estate. Real Estate Review, 28(4), pp. 57-62. 